HISPANICA 46 (2002)

\title{
Mujeres como protagonistas en el carnaval de España
}

\section{Oscar Javier MENDOZA GARCÍA}

\section{INTRODUCCIÓN}

Se aprecia en el Carnaval un carácter eminentemente social. Cada grupo social busca dar transcendencia a sus juegos y diversiones, a esas fiestas en que empezó a participar en la nin̄ez y que corresponden a cada fase de la vida. Unas veces serán los niños, otras veces los mozos, otras los hombres casados, y otras las mujeres casadas, quienes toman el protagonismo en determinadas acciones dentro de la diversidad que se da en el Carnaval. En estas páginas nos fijaremos exclusivamente en cómo actúan las mujeres en algunas de las acciones y juegos del Carnaval de España, dando por hecho el protagonismo femenino en fiestas de invierno de las épocas clásicas ${ }^{1)}$ : un estudio que pensamos merece la pena desarrollar para poder entender el Carnaval como la búsqueda de ese mundo al revés en que las mujeres, infravaloradas en tiempo ordinario, adquieren relevancia temporal para volver a la normalidad con la entrada de la Cuaresma.

Queremos comenzar expresando las necesidades básicas del hombre, comer y engendrar, vivir y hacer vivir, que requiere la fertilidad animal y vegetal. Estas necesidades son las que por naturaleza le han hecho al hombre fijarse en los cambios estacionales y no al revés. Esto, hemos de aclarar, se refiere a la zona templada de la tierra, cuyos cambios de estación son evidentes tanto en plantas como animales, especialmente el paso del invierno a la primavera. Esto hizo que los antiguos inventaran cultos mágicos que tenían como fin, no tanto dividir el tiempo cuanto alejar el invierno y atraer la primavera, estación que sincroniza la explosión vital de los tres reinos de la naturaleza: vegetal, animal y humano. Con esos ritos el hombre pretendía que la regeneración de la naturaleza y la fertilidad de los animales fuera eficaz para la conservación humana: vivir, procrear, y criar.

Aquellas fiestas agrarias de la antigüedad se fueron convirtiendo en la Edad Media, con el paso del tiempo y la impronta cristiana, en el Carnaval que ha 
perdurado hasta ahora. El Carnaval ha venido así a reunificar y compendiar antiguas fiestas populares a los dioses y diosas de la fecundidad: Osiris, Tammuz, Adonis, Atis, Cibeles, Artemisa, Perséfone, Atenea, Minerva, Deméter, Ceres, Baco, Saturno, Astarté (Dea Syria romana), Afrodita, Mithra y Herta ("Madre Tierra"), entre otros. El Carnaval, como toda fiesta, no es sino un conjunto de ritos provistos de un significado: función de estimular mágicamente a la naturaleza para conseguir la fecundidad y riqueza para el tiempo venidero. Las mujeres en este aspecto han sido protagonistas en diversas fiestas antiguas de invierno y tienen mucho que decir y hacer en muchas acciones del Carnaval de España.

\section{FIESTA DEL ARADO}

Se da en la Alta Maragatería de León entre otros lugares. Allí, los pastores disfrazados con pellicas y subidos en zancos, ceñidos a su cintura esquilas y cencerros se atan en parejas a un arado que guían otros disfrazados de mujeres, que van surcando la nieve. Cantaban una canción que hacía alusión directa a las buenas cosechas y aumento de los rebaños ${ }^{2}$. El que sean mujeres fingidas las que conducen el arado no es tan extraño sabiendo que las mujeres de los maragatos son las que trabajan la hacienda al dedicarse ellos al comercio de pescado y otras cosas. Esta costumbre se observa también en la sierra de la Demanda, región de Cameros, al sur de La Rioja (Rioja Baja) y al norte de Soria, donde las mujeres de los pastores se quedan al cargo de la hacienda cuando ellos hacen la trashumancia en otoño; "se ve a mujeres en actividades agrícolas, en carnicerías, pescaderías y reparto a domicilio"3). En un lugar y otro se ha dado una rígida endogamia: sólo debían casarse entre sí mismos. Esta "fiesta del surco" se da en otras regiones de Castilla: se trata de competir sobre quién hace el surco más largo y más recto y más profundo con la yunta de mular y el arado. Hoy día esta competición se hace en muchos pueblos con tractor. Otra competición era el de la composición de aperos de labranza.

El protagonismo de las mujeres en la conducción del arado se da en Bulgaria, Croacia, Rusia y Alemania. En Siam, China, a finales de abril, es el rey temporero, que reina durante tres días, el que traza nueve surcos con el arado y va "seguido por las damas viejas que esparcen la primera simiente de la temporada" para asegurar una magnífica cosecha ${ }^{4}$. También otros autores relacionan la fiesta del 
arado con antiguos cultos agrarios ligados a la fecundidad que se mantuvieron vivos en fiestas de bodas y otros ritos de paso ${ }^{5}$. El hecho de que sean ritos de Carnaval y precisamente en tiempo de siembra nos hace pensar que se realizan para asegurar la fertilidad de los campos, que para eso se ara la tierra, y nadie más propio que las mujeres para tal fin, que también deben ser fecundas para poder perpetuar la propia especie humana.

\section{MÁSCARAS FUSTIGADORAS DE MUJERES}

La conducción del arado, como otras acciones, son más de carácter social: la economía pastoril de España que quería asegurar la fecundidad de ganados ha conservado esos ritos antiguos. El lobo fue un animal sagrado para los latinos pastores. Las Lupercalia parecen fiestas de preservación de los rebaños contra el lobo, con el fin último de que fecundaran. A pesar de que fueron prohibidas por el papa Gelasio en el 496, los ritos de preservación contra lobos y zorros han continuado en España así como las máscaras fustigadoras de mujeres y chiquillos. Merece la pena señalar también las fiestas invernales vascas de preservación de lobos y zorros, fiestas que ya había en Roma y Grecia. Tanto en Vascongadas como en otros pueblos europeos la riqueza, "pecunia", se expresa por la abundancia de ganado, "pecus". En Ataun (Guipúzcoa) llaman "Otsabilko" (recoger para el lobo) a la cuestación que hacen los niños el Jueves de Todos. En otros lugares se llama a esta cuestación la danza del zorro "azeri dantza". El zorro es un animal dañino y diabólico. ¿Será este un rito de expulsión del espíritu maligno?

La fecundidad de los animales incluye la de las mujeres. Queremos mencionar las máscaras fustigadoras de mujeres que podrían muy bien derivar de máscaras antiguas de rituales pastoriles. Es tal la cantidad de ejemplos de enmascarados que azotan a las mujeres que sólo mencionaremos algunos bien conocidos. Entre las botargas de Guadalajara (en otros lugares de Castilla la Mancha son los zancarrones, zamarrones y vejigueros), una de ellas surge en la fiesta de la Purificación que antes se celebraba el catorce de febrero, fecha más acorde con las Lupercales, y que ahora es la Candelaria, el dos de febrero, pero esa coincidencia es fortuita). El "colacho" de Castillo de Murcia en Burgos, rasga las medias de las mujeres y salta por encima de los recién nacidos para que la fecundidad que ya ha sido efectiva no frustre el crecimiento de los infantes con alguna desgracia ${ }^{7}$. Mayor es la variedad de 
máscaras gallegas y aragonesas en las que a pesar de tener en común un carácter masculino y amedrentador típico de las mocedades adivinamos siempre ese deseo de fecundación. El "Cachimorro" de la Guardia, Alava ${ }^{8)}$, "cachiberrio", "cachiburrio", o "cachidiablo" de otras partes de La Rioja y Castilla León, con una vejiga de cerdo va azotando a las mujeres. También lleva una vejiga hinchada en un palo la botarga de Montarrón de Guadalajara. En la bochincha, vejiga llena de aire, apreciamos el espíritu masculino. Otras veces, el cachiberrio lleva un palo con una gran mata de crines de caballo, como el "Tserrero" del país de Soule. Los mozos de Poza de la Sal de Burgos llevan un rabo de buey cada uno. Otros, hasta van con una piel de gato inflada y llena de paja, que nos hacen recordar las tiras de piel del macho cabrío o del perro sacrificado en las Lupercales romanas y con las que los Lupercos corrían y azotaban sobre todo a las mujeres en la espalda para que fueran madres pronto, pues hubo un tiempo en que las mujeres parían muy de tarde en tarde ${ }^{9)}$. Para Gaignebet, los lupercos eran disfrazados carnavalescos de macho cabrío o lobo que realmente fecundaban a las mujeres. No vale, dice, engañarse con la sofística latina ${ }^{10)}$. Los excesos que se daban en los carnavales de España provocaron algún que otro embarazo y lo que es peor, al estar enmascarados y con el bullicio de la fiesta, a veces ni la propia embarazada sabía quién había sido el padre. Es esta una de las fuertes razones por las que las prohibiciones de máscaras se repetían de forma sucesiva. La vejiga del cerdo se usa para hacer un budín en Cotobad, Galicia, llamado bincha o bandullo, del que queremos destacar aquí su "papel fecundante" en Carnaval, que en el caso de la del cerdo se hincha y se guarda para conservar y multiplicar el alma del cerdo anualmente ${ }^{11}$. En fin, la huella de las Lupercales con esta variedad de máscaras en nuestro Carnaval se hace evidente en los "cigarrones" de Laza y Verín de Galicia, así como en los guirrios de Lamas de la Ribera en León, que con un látigo o palo con vejiga de animal, casi siempre de cerdo, se dedican a golpear a todos, sobre todo a las mujeres ${ }^{12}$.

\section{PELELE}

Es un "muñeco de figura humana hecho de paja y trapos; por ejemplo los que antiguamente era costumbre mantear como diversión" ${ }^{13}$. Era manteado por el pueblo bajo en Carnaval ${ }^{14}$. Goya nos pinta a cuatro manteadoras del pelele en el lienzo de óleo El Pelele ${ }^{15}$. En Madrid, y en época posterior a Goya, son las 
muchachas las que se entretenían en mantear un pelele de trapo o de paja ${ }^{16}$. Para Rodrigo Caro, estos "dominguillos son unas figuras de soldados con sus lancitas, y los visten de colorado" y dice, son imagen de los primipila o pila romanos, los primeros en orden de batalla, "de la voz primus et pilum, que es el dardo o arma arrojadiza" 17) "Pila" eran los muñecos que los esclavos romanos ponían en la fiesta de la Compitalia (del diecisiete de diciembre al cinco de enero). Se creía que así se evitaba que entraran los espíritus de los muertos en las casas para atacar. Se ponían en las "compita" (mojones de labrantío), y encrucijadas. Las personas libres ponían los "maniae" con la misma intención, en honor a Mania, madre de los espíritus. Quizá este rito se ha asociado con el Carnaval por el trato de superioridad que se daba a los esclavos en las Saturnales ${ }^{18)}$.

En el sentido que nos habla Frazer, que dice que estos muñecos eran sustitutos de personas en costumbres sacrificiales anteriores, cabría emparentarlos con los peleles que las cofradas de Santa Agueda queman como venganza femenina ante la supremacía del hombre. Cabe mencionar el pelele de Zamarramala, Peropalo o Pedropérez, al igual que esos muñecos que echaban a los toros y que ya los antiguos hacían denominándolos "dominguillos" y "pilas".

En la capital de Valladolid, al igual que en muchos otros pueblos, las mozas agarraban el "cobertor" y colocaban al pelele en el centro, tirándolo a lo alto mientras cantaban. Cuando alguna soltaba la manta por la risa o adrede, el pelele caía despanzurrado y saliéndosele la paja por las descoseduras ${ }^{19)}$.

\section{MAZAS}

Una de las acepciones de "maza" es "trapo u otra cosa que se prende al vestido de alguien sin que se dé cuenta para burlarse". La acepción más conocida en Carnaval lo define como "palo, hueso u otra cosa que se ataba por diversión a la cola de los perros u otros animales en carnaval" ${ }^{20)}$. Correas nos dice que "En algunas partes ponen a los perros calabazas por mazas por Antruejo, y a veces llenas de tascos con fuego y agujereadas, para que ardan los tascos y corran por las calles los perros" 21).

Se ha de pensar que lo que en principio era persecución de animales, esto es, atarles vejigas, mazas y hasta tascos, se ha desarrollado más tarde en un prender objetos a otras personas con el objeto de reírse de ellas. Esta diversión era de las 
muchachas en el Carnaval madrileño del siglo XIX. Consistía en que las muchachas se deslizaban "de puntillas por la calle para prender una maza o rabo de papel a los que pasaban por la calle, mientras que otras cantaban: "Daca la maza, que la lleva el borriquito que va a la plaza" ${ }^{22)}$.

\section{AGUAS Y PEDREAS}

El domingo de Carnestolendas por la tarde en el Madrid del s. XVII, dice Zabaleta, son las mujeres las que echan agua a los mozos. Unas veces son las criadas que después de comer, "se dividen por los balcones o ventanas, con pucheros en las manos. Los criados las socorren de calderos de agua, que arrojan con los pucheros sobre los pobres que pasan". Otras veces son las mujeres en general las que están "atalayando a los hombres que pasan para mojarlos" con "agua maldita" del demonio. A veces son "mujeres hermosas" las que mojan con "festiva agua" a "tres o cuatro caballeretes mozos". Estos caballeros respondían arrojando "dentro de la pieza muchas bombas de agua olorosas, hechas de cáscaras de huevos" 23). En otras ocasiones eran "pedreas galantes" con peladillas, figuras de confitería u otros dulces y siempre caballeros y ciudadanos iban "diciendo coplas y cosas para reír", siempre con un deseo de lujuria que esperaban satisfacer. No siempre eran "huevos de olor" (perfumados), en otros casos eran huevos que contenían "puras aguas de riñones" (bombas fétidas), piedrecitas o gruesos cantos $^{24)}$, pero, en cualquier caso, eran las mujeres las que llevaban la iniciativa de injuriar al pobre transeúnte. Las señoritas de Orense arrojaban el agua con jeringas ${ }^{25}$. También se ve en el Carnaval el arrojarse nieve, harina, salvado, ceniza, naranjas, tomates, calabazas y hasta echar hormigas en el baile para que se suban por las faldas de las mozas. En Jaén se tiraban con calabazas. En Canarias se tiraban huevos llenos con polvos de talco sobre amigos y enemigos ${ }^{26}$. $Y$ hasta gatazos se daban en Cádiz. Una broma del Pirineo aragonés oriental era que cuando las chicas "estaban en mayoría llegaban a desnudar a un hombre" ${ }^{27}$.

\section{JUEGOS DE OLLAS}

Caçalaolla "Es un juego muy ordinario, que se juega entre las mozas por el tiempo de carnaval" en el s. XVI: una hace de "olla de miel" y otra unida a ella por una cuerda trata de evitar que las otras golpeen a la "olla". Si la guarda alcanza a 
alguna sin soltar la cuerda, la guarda queda libre, la que era "olla" pasa a ser guarda y la alcanzada toma el puesto de la "olla" ${ }^{28)}$. En Galicia, nos dice Risco que se hacía el Domingo de Carnaval y que era juego de mujeres: consistía en lanzar una a otra pucheros al aire que había que recoger para que no se rompieran y aquella a la que por torpeza se le caía pagaba una multa ${ }^{29}$. Similar a esta forma de romper cacharros en la capital de Valladolid era el "jugar al cántaro" que consistía en colocarse las mozas en corro y con las dos manos echar el cántaro a la vecina para que lo cogiese en el aire, acompañando la acción con una tonada ${ }^{30}$.

En la antigüedad esta costumbre de romper un objeto para que vierta su contenido se realizaba, según Frazer, como ritual de vegetación y fertilidad, que hacen en toda China para recibir la primavera el tres o cuatro de febrero. Allí hacen una imagen de un buey de arcilla y repleto de grano; la gente lo apedrea hasta romperlo en pedazos esperando un año abundante. "En España y otros países, el primer domingo de Cuaresma se llama Domingo de Piñata. La piñata, que se rompe con gran algazara, tiene a veces forma animal o humana. Su interior contiene una colación de frutos secos y frescos, golosinas y juguetes. Puede verse en esta costumbre una supervivencia degenerada de la antigua usanza" ${ }^{31)}$. La palabra piñata está tomada del italiano "pignatta", olla, derivado de "pigna", piña, "por la semejanza de forma de las ollas antiguas con este fruto" ${ }^{32}$ y el hecho de ser juego propio del baile de máscaras del primer domingo de Cuaresma hace pensar que se trata de un deseo de que el Carnaval no muera y continúe de alguna forma aun en la Cuaresma.

\section{COLUMPIO}

En uno de los cartones de Goya para los tapices reales (1779, Prado) son mujeres las que se balancean. En otro cuadro (de Montellano, 1786-1787) Goya pinta a cinco gitanos en el que también se balancea una mujer ${ }^{33)}$. En Andalucía "es juego común de las mozas, y la que se columpia está tañendo un pandero y cantando" ${ }^{34}$. Rodrigo Caro dice en el s. XVII que es "entretenimiento de mozuelas" y "es uso de todo el año" ${ }^{35}$ ). En cuanto al tiempo de columpiarse, aunque no en total desacuerdo con el personaje de Rodrigo Caro, Don Diego, Julio Caro dice que es costumbre que va del solsticio de invierno hasta tres días antes de la Cuaresma ${ }^{36}$. Blanco White dice más claro que en el s. XVIII es de Carnaval, en Andalucía ${ }^{37}$. En 
Cádiz es costumbre que va de Navidad hasta cuando termina Carnaval que es cuando los "descuelgan" 38). También en Marruecos se hace en Carnaval ("Akura"). En Andalucía tenían tambien la bamba, columpio entre dos balcones, que jugaban los jovenes de ambos sexos cantando canciones de cuatro versos, algo parecido a una nana, aunque con ritmo algo más animado ${ }^{39}$. En Atenas y Roma estaba relacionado con festivales para fertilizar la tierra y promover el nacimiento y crecimiento de las plantas. Frazer dice que entre los estonianos eran las muchachas las que se balanceaban el día de San Juan Bautista, quizá emulando el balanceo del sol que ese día alcanza su máxima altura ${ }^{40}$. En la historia se hacía por muchas razones, entre otras: en la cosecha, en la pesca, para curar enfermedades, como expiación de suicidios y como rito de purificación y en primavera para dar fertilidad a las plantas y asegurar viento fresco en épocas de calor.

\section{CORRER GALLOS}

Correr gallos es "diversión de Carnaval, que consistía en herir con la espada, llevando los ojos vendados, un gallo convenientemente sujeto" ${ }^{41}$. Dicen que se ha introducido en Carnaval para significar la mortificación del apetito carnal que llega con la Cuaresma, "por cuanto esta ave es lujuriosa" 42). El gallo es así símbolo de la lujuria que es matado al llegar el tiempo de represión carnal cuaresmal.

Las "águedas" son las que cortan el cuello al gallo después de enterrarlo hasta el cuello en Pozal de las Gallinas, Valladolid. Las cofradas que habían cortado alguna cabeza, la ensartaban en un varal y la paseaban por todo el pueblo, en una clara alusión a la masculinidad derrotada ${ }^{43}$. También las mujeres son protagonistas en el barrio de San Vicente de Tordesillas donde, según nos comentaron personalmente los antropólogos Sr. Joaquín Díaz y Sr. Antonio Sánchez del Barrio, lo realizan aún y cortan el cuello de los gallos con una especie de "katana" pequeña. Son las cofradas de San Vicente, o en su defecto las mozas de la localidad las que ejecutan a cinco gallos colgados por las patas de una cuerda ante la ermita de San Vicente ${ }^{44}$. En Mucientes, otro pueblo de Valladolid, había un tribunal de mujeres que hacían el "juicio de los gallos"; formaban el tribunal la mujer con más mando efectivo en el pueblo, la señora mayor, una de las mozas "quintas" y tres representantes de asociaciones de la localidad ${ }^{45}$. También se da este juicio en otros pueblos como Mecerreyes, Burgos, aunque aquí son los mozos y el "zarragón" o "zamarraco" los 
que simulan enterrar al gallo pinchándole en los ojos con la espada, que hace de asador, y quienes comen el gallo ${ }^{46}$. En Poza de la Sal, Burgos, cada moza debía bailar con un solo pie al son de la gaita y cortar la cabeza del gallo a los tres golpes. Similares escenas se repiten en muchos otros pueblos castellanos ${ }^{47}$. En tierras vascas, "Oillokunde", es nombre femenino de la fiesta del "jueves de gallinas" ${ }^{48}$. En Galicia, Frazer aplica este rito a las mujeres, que llevan el gallo sobre una corona de la cosecha con una pértiga ${ }^{49}$. En pueblos de Soria, Burgos, Zamora y otras provincias son las mozas las matadoras del gallo ${ }^{50)}$.

\section{FIESTA DE LAS AGUEDAS}

La fiesta de Santa Agueda es celebrada en toda España por las mujeres el cinco de febrero. En Urgel, Lérida, las mujeres tienen un mando relativo estos días, se disfrazaban e iban con la cara tapada acometiendo a los transeúntes y diciéndoles burlas, hacían cuestación, tocaban las campanas, bailaban solas o elegían pareja. En Juncosa, las mujeres van con la cara cubierta burlándose y acometiendo a la gente; las casadas pueden hasta emborracharse. En Castronuevo, Zamora, hay una cofradía de mujeres que rigen dos mayordomas y son las que hacen cuestaciones, las que eligen compañero de danza, que parece ser muy sensual, y todas cenan en la casa de una de las mayordomas. En Frades, Salamanca, las mayordomas van siempre con dos célibes que han elegido y a los que llaman "zánganos" (entre las abejas son quienes fecundan a la reina) expresando el deseo de asegurar la fecundidad. En otros pueblos de Salamanca llaman al grupo de mujeres "Aguedas mágnedas" y son las anfitrionas de la merienda que acaba en una orgía dionisíaca. En Zamarramala, Segovia, dos alcaldesas reciben "la vara de la justicia y la autoridad... aquel día mandan ellas". Sólo las mujeres casadas y viudas asisten al baile. En La Rioja también las mujeres tienen el mando estos días y son las mozas las que tocan las campanas en pueblos como Robres del Castillo y Agoncillo (no en Ojacastro, entre otros pueblos del valle del río Oja, que son mozos quien las voltean), y sólo las mujeres, "sin mezcla de varones", celebran la fiesta de Santa Agueda el cinco de febrero merendando y bailando ${ }^{51}$. Similares costumbres se dan en Castilla León y en Guadalajara ${ }^{52)}$. Las intenciones de las Matronalias romanas se nos hacen evidentes en estas fiestas de mujeres casadas. 


\section{JUEVES DE COMADRES}

Finalmente hemos de añadir las fiestas de compadres y de comadres. Comadre es aquí persona allegada, vecina y amiga y no sólo la que tiene un vínculo por razón del bautismo o de la boda. La fiesta "Emakunde" o "Andrakunde" vasco navarras coinciden, incluso en el nombre, con las Matronalia. En Andalucía occidental se ha celebrado de modo similar a como se celebraba la fiesta de San Valentín el catorce de febrero, eligiendo pareja de forma artificiosa para realzar amistades que a veces terminaban en boda. En Rociana, Huelva, distinguen el "Jueves lardero", el "Jueves de comadres y de compadres" y el "Jueves de los chiquillos". Sobre cuándo eran cada cual no hay regla general. En la villa de La Solana, de la Mancha, el "día de la comadre" era el jueves antes de Carnaval. Nos confirma Covarrubias que el "jueves de comadres" es el jueves anterior al martes de Carnestolentas, cuando las mujeres amigas se juntan a merendar, reñir y sacar chismes ${ }^{53}$. Lo que sí podemos afirmar es que aunque suelen coincidir con las "kalendae" de marzo, son fiestas que se han ajustado al calendario cristiano y por tanto dependen de cuando empiece la Cuaresma. En Viana del Bollo, Orense, el "jueves de compadres", las mujeres hacen un muñeco, el compadre, de pajas de centeno. Lo ponen en el balcón y lo defienden de los hombres que tratan de cogerlo para quemarlo. También los hombres hacen una comadre que el "jueves de comadres" ponen en la punta de un mayo hasta el martes de Carnaval. En Carballal, Lugo, las mozas hacían comadres el "jueves de comadres" que los mozos después quemaban y el "jueves de compadres" hacían los compadres con intención de quemarlos ellas. En otros lugares de Galicia, como en Castro de Caldelas, Orense, las mozas hacían los compadres y los mozos las comadres que después ellos mismos quemaban ${ }^{54}$. En Escurial, Cáceres, son las niñas las protagonistas del "jueves de comadres" que en comparsas recitan romances a las autoridades ${ }^{55}$.

En muchos pueblos del norte de España sigue celebrándose el jueves anterior al martes de Carnaval que llaman "Jueves de Todos" en el que las mujeres se siguen reuniendo para merendar. Quizá esta denominación quiere reunir todas las anteriores, de compadres, comadres y hasta de niños, pero lo cierto es que con la emigración de los pueblos a las ciudades y al quedar tan poca juventud, las mujeres, que desde siempre y en muchos casos se ocupaban de la preparación de la merienda-cena, en nuestros días se llevan la exclusividad del protagonismo de la 
fiesta en muchos pueblos de España.

\section{CONCLUSIÓN}

Repasando algunas de las acciones del Carnaval de España en las que las mujeres son protagonistas, hemos observado un recuerdo a esas fiestas agrícolas de pueblos del mediterráneo oriental que celebraban con el paso a la primavera. Según tiempos y lugares los nombres de los dioses varía: Osiris, Dionisio, Baco, Adonis y Tammuz. El culto a Cibeles, que comenzaba con la tala de un pino llevado al templo de la diosa, donde colocaban la figura de un joven, representante posiblemente de Atis, parece ser precedente del "meco" (procedente por exairesis de muñeco) de Galicia. Las Saturnales romanas, que en definitiva defienden la igualdad de los hombres, quedan reflejadas en ese mando temporal que adquieren las mujeres en Carnaval. De otro modo, también quedan reflejadas las Saturnales en tantas fiestas de "reyes" que se hacen desde la Edad Media y no hemos mencionado: los reyes de Navidad, los reyes de mozos, de porqueros y pastores, el rey y reina de gallo, los estudiantes "obispillos" de San Nicolás, los cantores "Inocentes", el rey de la "Haba" o "faba" en Epifanía. Al igual que la fertilidad femenina, la potencia mágica del rey saturnalicio se extiende a todo lo que le rodea, fertiliza la tierra y hace fecundos a los animales. Quizá la coronación de espinas de Jesucristo (Mc. 15,1620) declarándole rey de los judíos tenga semejanza con aquel deseo de renovación vital que buscaban con el efímero reinado y muerte del rey cómico saturnalicio. De las "Compitalia" (cuatro y cinco de enero) en que colocaban munecos en las casas con fines preservativos vemos esa misma fabricación de muñecos de pasta y embutidos en Carnaval, días en que también las mujeres mantean esos peleles y por ampliación a los perros y gatos. De las "Lupercalia", diecisiete de febrero, nos quedan las mismas flagelaciones a las mujeres por parte de los hombres enmascarados con fines fecundantes, así como la preservación de ganados contra fieras como el lobo. En la "Consualia", doce de diciembre, se paseaba a asnos, caballos y mular adornados y con fin preservativo, que tambien se hace de Navidad a San Antón, fiesta en que se hace el rodeo de templos con el ganado. De las "Matronalia", uno de marzo, queda la misma fiesta de las mujeres casadas con regalos y banquetes en Santa Agueda, cinco de febrero. De "Isidis Navalis", cinco de marzo, quedan las mismas mascaradas con paseo de un barco en ciudades como 
Reus y Salou, Cataluña. De la "Mamuralia", catorce de marzo, queda en Año Viejo la quema y baqueteo de un monigote o pellejo que representa al año saliente (viejo). Todas ellas son fiestas en las que se representa la lucha entre el invierno y la primavera, a veces simbolizada en pantomimas, con la consiguiente victoria e instauración de la primavera.

El ritmo festivo, de mediados de diciembre a comienzos de marzo, es bastante parecido en el calendario pagano de los últimos tiempos del Imperio Romano y en el cristiano. Son similares también la forma especial como participan y actúan las mujeres. La sociedad cambió de credo pero no de intereses básicos: trabajar, comer, crecer y multiplicarse. Los viejos rituales paganos quedaron, si no adscritos al Carnaval de modo directo y en las mismas fechas, sí ajustados al santoral de un modo general en este período que en sentido amplio llamamos Carnaval, considerado como tiempo que va desde Navidad hasta el Miércoles de Ceniza. Este período del Carnaval es homogéneo, incluso en sus nombres, a todo el Occidente cristiano, y hasta al mundo musulmán, gracias a la fuerza expansiva imperial romana que conlleva la difusión del cristianismo. Pero esa mezcla de ritos paganos y cristianos no se consiguió sólo con tal expansión romana, habría que hablar más bien de transmisiones de culturas antiguas hechas a lo largo de la Edad Media y que dan como resultado una homogeneidad folklórica en diferentes países de Europa. El cristianismo, con su teología, y la vida social de los pueblos del Medioevo hasta nuestros días son quienes han aglutinado aquellas prácticas antiguas condensándolas especialmente en los días que anteceden a la Cuaresma y significando valores contrarios a ella sin perder por otra parte aquel contacto con la naturaleza y el deseo de alejar el invierno y hacer resurgir la vida. El Carnaval con esa riqueza de significación que se aprecia en sus acciones es más que una adaptación de aquellos ritos paganos de fertilidad: representa al Paganismo en sí frente al Cristianismo, los valores carnales (paganos) frente a los espirituales (cristianos). De este modo, a más fuerza social de la Iglesia más sentido han tenido los actos carnavalescos como contrarios a los cuaresmales. Las prohibiciones tanto de las Bacanales como de los excesos del Carnaval han sido siempre ineficientes, al contrario, los han promovido. Los documentos más antiguos que nos quedan del Carnaval son las prohibiciones de la Iglesia, que nos hablan de estas acciones. La transgresión de la ley ha sido el "modus vivendi" del Carnaval, lo que le ha 
permitido seguir con vida. Es así el Carnaval, la fiesta de locos para no caer en la locura, la fiesta de saltarse la prohibición para liberarse de caer en la neurosis. ¡Cuánto stress y depresiones se habrán evitado en la historia gracias al Carnaval!

A pesar de que la Iglesia fue sustituyendo fiestas paganas dándoles su espíritu religioso cristiano, aquellas tradiciones paganas han continuado impregnadas con el sentido religioso en los Carnavales populares. Sin embargo, el Carnaval, no son tanto cambios de significación de ritos antiguos cuanto, acciones que indican la existencia de unos rasgos muy permanentes de los grupos humanos con voluntad de expresar ciertos intereses esenciales bajo formas parecidas: disfrazarse, insultarse, comer y beber en exceso, violencia en fin, salirse de la norma y lo cotidiano, que en eso consiste la fiesta y en el Carnaval se da con mayor grado. Esas acciones son las que hemos de estudiar. Está bien estudiar los móviles primitivos de fiestas y ritos pero también es necesario ver los problemas de cada momento y lugar para apreciar el carácter social del Carnaval: se busca con el Carnaval un desequilibrio social en que un elemento determinado de la sociedad tiene un papel muy fijo y esencial. En este artículo hemos repasado acciones del Carnaval de España en que la mujer tiene algo que decir expresando lo que en ella es más característico, la fertilidad, algo fundamental para la vida humana y que era lo que pretendían con aquellas fiestas antiguas de las que el Carnaval ha recogido algunos rasgos en su forma de hacer sus ritos y juegos. La figura de la mujer resalta como actora a veces buscando esa revancha por el dominio de los hombres en tiempo ordinario tanto en aquellas fiestas antiguas como en el Carnaval de muchos pueblos de España, especialmente en la parte norte, de donde más datos hemos podido recolectar. Las mujeres, especialmente las casadas por su maternidad, tratan de realzarse sobre los hombres que en el contexto social ordinario son los cabezas de familia y ostentan los cargos públicos. Se convierten así las mujeres en las hacedoras por antonomasia del Carnaval. En algunos juegos, la mujer desarrolla el papel protagonista dominando a los hombres y ostentando la autoridad total durante unos días, buscando hacer ese mundo al revés que vuelve a su normalidad con la entrada en la Cuaresma. La mujer, en cuanto madre, se convierte en símbolo de la fecundidad de la vida orgánica en general que en definitiva trata de responder a las necesidades vitales humanas: vivir y hacer vivir. 


\section{Notas}

1) Oscar Javier Mendoza García, "Protagonismo de las mujeres en antiguas fiestas carnavalescas", en The Journal of Humanities and Sciences, $\mathrm{n}^{\circ}$. 6, Institute for the study of humanities and sciences Takushoku University, Tokio, 2001, pp. 15-28.

2) Antonio Sánchez del Barrio y José Luis Alonso Ponga, El Carnaval, Cuadernos Vallisoletanos $\mathrm{n}^{\circ} .22$, Valladolid, 1987, p. 15. Se hacía el uno de enero frente a la iglesia y se pedía por la fecundidad de ovejas y cabras: Julio Caro Baroja, El Carnaval, Taurus Ediciones, Madrid, 1979, pp. 239-243.

3) Luisa Yravedra y Esperanza Rubio, Leyendas y tradiciones de la Rioja, Instituto de estudios riojanos, Logroño, 1980, p.97.

4) Sir James George Frazer, La Rama Dorada. Magia y religión, Fondo de Cultura Económica, Madrid, 1984, p. 333.

5) Sánchez del Barrio y Alonso Ponga, op. cit. p. 15.

6) Caro Baroja, op. cit., pp. 357-358. En pueblos de León son las paridas las que hacían ofrenda que consistía en seis velas, una paloma y un pan (p. 359).

7) César Justel, España. Fiestas populares, Al y Mar, Madrid, 1997, p. 69.

8) Caro Baroja, op. cit., dibujos de G. Manso de Zúñiga, en p. 181 del cachiberrio de la Guardia, y en p. 213 de "Zaldiko-maldiko" de las fiestas de Pamplona.

9) Publio Ovidio Nasón, Fastos, Gredos 121, Madrid, 1988, libro II, pp. 425-431.

10) Claude Gaignebet, El Carnaval, ensayos de mitologia popular, Editorial Alta Fulla, Barcelona, 1984, (título de la edición original: Le carnaval, Essais de mythologie populaire, Editions Payot, París, 1974), pp. 18-19. El Macho Cabrío Expiatorio aparece ya en el Antiguo Testamento; $\mathrm{Al}$ mismo Moisés se le representa con cuernos.

11) Ib. p. 42 y p. 44.

12) Justel, op. cit., p. 72 (guirrios) y p. 921 (pelliqueiros de Laza, Orense). La Morena es el personaje que sale tras los peliqueiros de Laza, porta una cabeza de vaca y persigue sobre todo a las mujeres: Luis Agromayor, España en fiestas, Aguilar, Madrid, 1987, p. 381.

13) María Moliner, Diccionario de uso del español, Gredos, Madrid, 1996, edición en línea.

14) Julio Casares, Diccionario ideológico de la lengua española, $2^{\text {a }}$ edi., Gustavo Gili, Barcelona, 1995, p. 635, col. 1. Julio Casares sigue a la Real Academia.

15) Clásicos del Arte Noguer - Rizzoli 47, La obra pictórica completa de Francisco de Goya, Introducción de Rita de Angelis, Noguer, Barcelona - Madrid, 1975, Lámina IX, Cartones para los tapices reales 8, El Pelele, Madrid, Museo del Prado. Ver El Pelele de la Torrecilla, Madrid, (n. 274). Se aprecia también el protagonismo de las mujeres en uno de los grabados de Goya, el Disparate Femenino, p. 14. 
16) Caro Baroja, op. cit., pp. 64-65. Julio Caro, apoyándose en personajes de Carnaval como "Peropérez" o "Peropalo" y en el diminutivo vasco acabado en "ele", dice que podría derivar de Pedro pero no nos parece razón suficiente.

17) Rodrigo Caro, Días geniales o lúdicros, t. I, Espasa Calpe, Madrid,1978, p. 63.

18) Sir James George Frazer, The Golden Bough, part. V, "The Spirits of the Corn and of the Wild" vol. 2 , New York, 1922, pp. 94-108.

19) Sánchez del Barrio y Alonso Ponga, op. cit., p. 19.

20) Moliner, op. cit., en línea.

21) Gonzalo Correas, Vocabulario de refranes y frases proverbiales y otras fórmulas comunes de la lengua castellana, Visor, Madrid, 1992, p. 296, b. Tasco es estopa gruesa de cáñamo o lino.

22) Caro Baroja, op. cit., p. 63.

23) Juan de Zabaleta, El día de fiesta por la mañana y por la tarde, Clásicos Castalia, Madrid, edi. de Cristóbal Cuevas García, 1983, cap. XI, pp. 445-452.

24) Ricardo Martín Tobías, La Magia del Carnaval, Corondel, Barcelona, 1993, pp.57-58.

25) Vicente Risco, "Notas sobre las fiestas de Carnaval en Galicia", en RDTP (Revista de Dialectología y Tradiciones Populares) IV, 1948, p. 170-171. También Zabaleta comenta que dos mujeres usaban "un instrumento de disparar agua", op. cit., p. 449.

26) Gilberto Alemán, El Carnaval. La fiesta Prohibida, Centro de la Cultura Popular Canaria, Tenerife,1996, p. 115.

27) José Lisón Huguet, Algunos aspectos del estudio etnográfico de una comunidad rural del Pirineo Aragonés Oriental, Institución "Fernando el Católico", Zaragoza, 1984, p. 175.

28) Ver "Caçalaolla" (voz corrompida del vocablo "Caza la Olla") en Sebastián de Covarrubias y Orozco, Tesoro de la lengua castellana o española, ed. de Felipe C.R. Maldonado, revisada por Manuel Camarero, Castalia, Madrid,1994, p. 290.

29) Risco, op. cit., p. 174.

30) Sánchez del Barrio y Alonso Ponga, op. cit., p. 17.

31) Frazer, La Rama Dorada. Magia y religión, op. cit., p. 532, nota 1.

32) J. Corominas, Diccionario crítico etimológico de la lengua castellana, t. III, Francke, Berna, 1970, p. 799.

33) Clásicos del Arte Noguer - Rizzoli 47, op. cit., El Columpio (n. 95) del Museo del Prado de Madrid y El Columpio (n. 202) de Montellano, Madrid.

34) Covarrubias y Orozco, op. cit., p. 335. Dice es un juego muy antiguo pues el verbo ya aparece en la Grecia clásica y los romanos especialmente en las fiestas al dios Baco columpiaban peleles. Podría derivar de "colo" porque parece estar colgada la persona que se columpia del cuello. Corominas apunta que en griego "xolumban" es zambullirse, voz 
que entra al castellano por medio del leonés y que el latín "columbium" es piscina: J. Corominas, op. cit., t. I, p. 859.

35) Rodrigo Caro, op. cit., t. II, p. 189.

36) Caro Baroja, op. cit., p. 59.

37) Blanco White, Letters from Spain, 2 edi., Henry Colburn, London, 1825, p. 238.

38) Armando Palacio Valdés, Los majos de Cádiz, Oviedo, (GEA: Grupo Editorial Asturiano), Itsmo, Madrid, 1995, p. 280. Hemos de interpretar que el Carnaval de que nos habla el autor se entiende como lo que etimológicamente expresa la palabra en forma restringida, esto es, el final del período en que se come carne, el día que precede a la Cuaresma, por lo que se deduce que se refiere al martes anterior al Miércoles de Ceniza. El "ultimo día de columpio" es pues el Martes de Carnestolendas y no tres días antes de Cuaresma como interpreta Julio Caro Baroja. El autor no dice más que, el "descolgar" los columpios, esto es, desatarlos y deshacerlos, se hace al terminar el período de Carnaval.

39) Caro Baroja, op. cit., p. 60. Aunque para Covarrubias "bamba" es nombre similar a bambarria, con el significado de tonto o bobo, creemos es más acertado seguir a Corominas que dice pertenece a bambolear, con el significado de oscilar, voz de creación expresiva que aparece ya en 1550 y se usa en Andalucía y Salamanca y hasta en Cuba, Honduras (BRAE VII, 298): Corominas, op. cit., p. 383.

40) Frazer, "Swinging as a magical rite", en The Golden Bough, part. III, op. cit., pp. 277-285. En Siam, los brahmanes "rasgaban el aire en un columpio suspendido de dos altas pértigas de hasta treinta metros de altura", "podría pensarse que cuanto más altos subiesen los brahmanes al columpiarse, más alto crecería el arroz" (el rito es del festival de recolección): Frazer, La Rama Dorada. Magia y religión, op. cit., p. 334 y p. 338.

41) Casares, op. cit., p. 411, col. 3. Sobre otras variantes de "correr gallos" ver Moliner, op. cit., donde señala que al gallo se le entierra hasta el cuello o se corre tras él para cortarle la cabeza, y Oscar Javier Mendoza García, "El gallo de Carnaval en España", Hispánica 42, 1998, p.144.

42) Covarrubias y Orozco, op. cit., p. 575. La construcción transitiva de "correr" equivale a "expulsar, despedir, echar (de un lugar)", ver Corominas, oc. cit., p. 913. Este significado que se halla en textos medievales es el más propio de la acción de correr gallos como símbolo del final del Carnaval que se expulsa.

43) Sánchez del Barrio y Alonso Ponga, op. cit., p. 11. Las "águedas" son el grupo de mujeres casadas que celebran una fiesta el día cinco de febrero, día de Santa Agueda, a quien cortaron los pechos al martirizarla y ha quedado como patrona de las lactantes sobre todo y para preservar a las mujeres de las enfermedades de pecho. Así como Santa Brígida, el uno de febrero, hincha las ubres de las vacas, el cinco de febrero, Santa Agueda protege a 
las nodrizas.

44) Ib., p. 13, nota 5. Lo mismo nos ha confirmado el guía de la iglesia museo San Antolín, contigua al barrio de San Vicente, testigo del rito.

45) Luis Díaz, Joaquín Díaz, y José Delfín Val, "El Cancionero Musical”, Catálogo Folklórico de Valladolid, vol. Institución Cultural Simancas, Valladolid, 1982, pp. 48-50. Quintas eran las chicas que cumplían la edad en que los chicos, quintos, tenían que ir a cumplir el servicio militar. Con el año 2001 en que se sortean los últimos quintos de la historia de España, las quintas desaparecen también. Personas de Mucientes nos han dicho que esta tradición de correr gallos, así como el reunirse las "águedas" en Carnaval, desaparecieron ya hace décadas y los pocos jóvenes que quedan nada saben ya de aquellas costumbres.

46) Jesús González Alonso, "La fiesta del gallo", Mecerreyes, año III, n. 10, Ayuntamiento de Mecerreyes, Burgos, 1987, pp. 13-16 y en año I, n. 0 (enero-marzo, 1985). En 1995 se subastó el gallo como se ve en año XI, n. 47, 1995.

47) Caro Baroja, op. cit., p. 87.

48) Ib., p. 88.

49) Frazer, The Golden Bough, part. V, op. cit., vol. 1, p. 277.

50) Caro Baroja, op. cit., p. 305.

51) Yravedra y Rubio, op. cit., p.96.

52) Caro Baroja, op. cit., pp. 372-382 y Nieves de Hoyos "Fiestas en honor de Santa Agueda, patrona de las mujeres", RDTP VII, 1951, pp. 446-456.

53) Covarrubias y Orozco, op. cit., p. 336.

54) Risco, op. cit., pp. 168-169.

55) Caro Baroja, op. cit., pp. 388-389. Sobre estas fiestas ver Cámara Cascudo, "Compadre e comadre", RDTP XII, 1956, pp. 258-259. 


\section{〈Resumen〉}

\section{Mujeres como protagonistas en el carnaval de España}

\section{Oscar Javier MENDOZA GARCÍA}

En el Carnaval de los pueblos de España perdura el recuerdo a esas fiestas agrícolas de pueblos del mediterráneo oriental que dan paso a la primavera. Observando algunas acciones del Carnaval de España como son la fiesta del arado, las máscaras fustigadoras de mujeres, el pelele, las mazas, agua y pedreas, el juego de ollas, el columpio, correr gallos, la fiesta de las Aguedas y el jueves de compadre y comadre, apreciamos que las mujeres adquieren relevancia momentáneamente. Este protagonismo de las mujeres era evidente ya en fiestas a dioses y diosas de la antigüedad así como en fiestas clásicas griegas y romanas.

Sin olvidar el significado que ha dado al Carnaval la Iglesia y la vida social medieval como ritos contrarios a la espiritualidad cristiana, no dudamos que esas costumbres de las culturas antiguas griegas y romanas son un precedente de nuestros carnavales. La época invernal de aquellas festividades y del Carnaval coincide, aunque en muchos casos las fechas varían. A pesar de que las fechas no se han acomodado de forma directa sí apreciamos muchas reminiscencias de ritos antiguos examinando acciones y juegos de lugares y tiempos concretos del Carnaval de nuestros pueblos españoles. En estos ritos, las mujeres se constituyen en protagonistas y hacedoras del Carnaval, realizando así ese mundo al revés en que ellas adquieren una autoridad pasajera y expresan la fertilidad que les es propia dándose así relevancia y siempre con el deseo de que la naturaleza se renueve y sea fértil para que la conservación y permanencia del ser humano se hagan posibles. 